\title{
Síndrome de Marfan
}

\author{
Miguel Marx ${ }^{1}$; Eudes Alves Simões Neto ${ }^{2}$; Maria Nizete Tavares Alves ${ }^{3}$; \\ José Marcondes Macêdo Landim ${ }^{4}$; Martha Maria Macedo Bezerra ${ }^{5}$
}

\begin{abstract}
Resumo: O presente estudo consiste numa revisão bibliográfica das bases de dados PubMed e Scielo. Os artigos foram buscados utilizando a expressão Marfan Syndrome. Obteve 239 artigos de livre acesso no PubMed e 06 no Scielo, foram selecionados 37 trabalhos mais relevantes dos últimos cinco anos no tocante aos aspectos genéticos, fisiopatologia, diagnóstico e tratamento, e mais sete de datas anteriores, devido a sua importância histórica. Síndrome de Marfan é uma doença sistêmica, autossômica dominante do tecido conjuntivo causada por mutações nas proteínas da matriz extracelular, especialmente a fibrilina-1. Afeta principalmente os sistemas cardiovascular, esquelético e olhos. As manifestações mais freqüentes são: aneurisma de aorta torácica, luxação do cristalino ocular e crescimento exagerado de ossos longos. Há um novo entendimento sobre o papel da regulação do fator de crescimento tumoral $\beta$. Esta revisão destaca fisiopatologia, manifestações clínicas, tratamento padrão, bem como opções terapêuticas inovadoras. Considera importante o acompanhamento multidisciplinar, objetivando o diagnóstico precoce, reduzindo a morbimortalidade dos indivíduos afetados.
\end{abstract}

Palavras-chave: Síndrome de Marfan; FBN1; Diagnóstico; Tratamento; TGF- $\beta$.

\section{Marfan Syndrome}

\begin{abstract}
This study is a review of the PubMed and Scielo database. Articles were searched using the terms Marfan Syndrome. We obtained 239 freely accessible articles on PubMed and 06 on Scielo, we selected 37 most relevant papers of the last five years, related to genetic aspects, pathophisiology, diagnostic and management, and 07 oldest because of their historic importance. Marfan syndrome is a systemic autosomal dominant connective tissue disease caused by mutations in the extracellular matrix proteins, especially the fibrillin-1. Affects primarily the cardiovascular, skeletal and eye. The most frequent manifestations are: thoracic aortic aneurysm, dislocation of the ocular lens and overgrowth of long bones. There is a new understanding of the role of regulation of tumor growth factor $\beta$. This review emphasizes pathophysiology, clinical manifestations, standard treatment and innovative therapeutic options. Considers the importance of a multidisciplinary follow, aiming at early diagnosis, reducing the morbidity of affected individuals.
\end{abstract}

Keywords: Marfan syndrome, FBN1, Diagnosis, Treatment, TGF- $\beta$.

\footnotetext{
${ }^{1}$ Médico Perito Federal, Servidor da Universidade Federal do Cariri, Médico do Trabalho do Hospital Regional do Cariri, mestrado em terapia intensiva. E-mail: miguel.marx@ufca.edu.br;

${ }^{2}$ Médico residente do Instituto de Infectologia Emílio Ribas (USP);

3 - Professora Assistente da Universidade Regional do Cariri - URCA. Curso de Enfermagem. Enfermeira da Secretária de Saúde de Juazeiro do Norte. Doutoranda em Ciências da Saúde na Faculdade de Medicina do ABC;

4 Mestre em Planejamento e Políticas Públicas pela UECE. Licenciado em Ciências Biológicas pela Universidade Regional do Cariri, Especialista em Botania, pela URCA, Gestão Escolar pela UDESC e Educação de Jovens e Adultos pela FJN. Ex-Secretario Municipal de Educação da Prefeitura Municipal de Barbalha (2006 a 2008). Atualmente é Professor Assistente e Diretor Geral da Faculdade de Juazeiro do Norte, Presidente do Conselho Municipal de Educação de Juazeiro do Norte e Professor rede pública Estadual do Ceará.

${ }^{5}$ Mestrado em Educação pela Universidade Estadual do Ceará. Pedagoga pela Universidade Regional do Cariri, Especialização em Língua Portuguesa pela Universidade Estadual do Ceará, Especialização em Políticas Públicas pela Universidade Regional do Cariri, Especialização em Saude Mental e Psiquiatria pela Universidade Estadual do Vale do Acaraú. Atualmente, cursa o Doutorado em Saúde Coletiva pela Faculdade de Medicina do ABC. Professora concursada da Secretaria de Educação do Estado do Ceará e Professora da Rede Municipal de Juazeiro do Norte, CE. E-mail: marthamacedo2016@gmail.com
} 
Id on Line Revista Multidisciplinar e de Psicologia

Id on Line Multidisciplinary and Psycology Journal

\section{Introdução}

A Síndrome de Marfan (SM) é uma doença sistêmica do tecido conjuntivo, descrita pela primeira vez há mais de 100 anos pelo professor parisiense de pediatria, Antoine Bernard Marfan, que percebeu a associação de dedos longos e outras alterações ósseas em uma garota de 05 (cinco) anos, Gabrielle. Hoje, o distúrbio que leva seu nome tem sido objeto de muita investigação clínica e molecular.

A incidência da SM é de cerca de 2 a 3 por 10.000 indivíduos, embora esta estimativa dependa do reconhecimento completo de todos os indivíduos afetados e geneticamente predispostos. Vários fatores podem contribuir para uma subestimação da prevalência da doença. Isso porque tanto o fenótipo torna-se mais evidente com o aumento da idade, quanto por muitas das manifestações exteriores serem comuns na população em geral. Deve-se levar em consideração que esta desordem segrega esporadicamente um traço dominante em cerca de $25 \%$ dos casos, resultantes de mutações novas, e que a predominância está na mutação do gene FBN1, que codifica a proteína da matriz fibrilina- $1^{(1)}$.

A doença ocorre em todo o mundo, sem predileção por sexo. Algumas alterações são comuns em pessoas não afetadas. A alta estatura com crescimento ósseo exagerado, por exemplo, estão aumentados em atletas de vôlei e basquete, levando até a recomendação que se realize um screening ecocardiográfico nestes indivíduos. Alguns deles apresentam alargamento da raiz da aorta maior que $4,5 \mathrm{~cm}$, e outros são diagnosticados com $\mathrm{SM}^{(2)}$. Estes dados parecem indicar uma maior incidência na população selecionada.

Devido à alta incidência de aneurisma da aorta associado à dissecção, o tempo de vida muitas vezes é abreviado. Entretanto, antes da existência da correção cirúrgica da raiz da aorta, a mortalidade era muito maior. Em 1970, um relato sobre a expectativa de vida e causas de óbito na SM descreveu que a expectativa de vida em indivíduos afetados era de 2/3 (dois terços) em relação a indivíduos normais. A causa de morte foi cardiovascular em mais de $90 \%$ dos casos (dissecção aórtica, insuficiência cardíaca congestiva, ou doença valvar). No entanto, uma avaliação mais recente descreve uma expectativa de vida quase normal, indicando a melhora no diagnóstico e tratamento dessas condições ${ }^{(3)}$. 
Id on Line Revista Multidisciplinar e de Psicologia

Id on Line Multidisciplinary and Psycology Journal

\section{Fisiopatologia}

Primeiramente, a deficiência de elastina era tida como a principal causa da Síndrome de Marfan, por conta da pele e da aorta dos afetados apresentarem diminuição no teor de elastina e fragmentação de fibras elásticas. Entretanto, as manifestações em tecidos sem elastina, como osso e zônulas ciliares, acabou por excluir o seu gene das mutações primárias que causariam o distúrbio. Soma-se a isso, o mapeamento que localizou o gene mutante envolvido na SM no lócus 15q11.2, um tanto distante do lócus cromossômico da elastina, que fica em 7q11.2 ${ }^{(4)}$.

Sakai e colaboradores ${ }^{(5)}$ identificaram pela primeira vez a fibrilina-1 como principal componente das microfibrilas da matriz extracelular, presente em todos os tecidos com manifestações clínicas da Síndrome de Marfan. A análise mutacional do gene FBN1 em pacientes afetados encontrou alguns pacientes não relacionados com mutações missense (pontuais) ${ }^{(1)}$. Até hoje, as extensas e detalhadas análises de mutações e "linkage" indicam ausência de heterogenicidade de lócus para a apresentação do fenótipo clássico de Marfan ${ }^{(6)}$.

O gene da fibrilina-1 contém 65 éxons, mede 235 KB de DNA genômico e codifica uma glicoproteína de $350 \mathrm{kDa}$, altamente conservada entre diferente espécies. As mutações, em sua maioria, ocorrem em certo número de fatores semelhantes ao fator de crescimento epitelial, repetido em tandem 47 vezes. Isso causa uma ruptura nos resíduos de cisteína do gene da fibrilina. Estes, por sua vez, interagem via ligação dissulfeto na determinação do domínio da proteína, afetando a ligação do cálcio à proteína e, como consequiência, levam ao aumento da clivagem ou proteólise da fibrilina ${ }^{(7)}$.

Muitas descobertas têm sugerido que a dominância na SM se dá por atividade inadequada da proteína mutante em depósito ou pela função da proteína normal codificada pela cópia normal do gene $F B N 1$, também chamado de efeito dominante negativo. Em primeiro lugar, este era um quadro bem estabelecido para outras doenças do tecido conjuntivo, como Osteogênese Imperfecta. Em segundo lugar, os monômeros da fibrilina-1 se agregam em estruturas complexas chamadas microfibrilas, proporcionando uma oportunidade de interferências. Em terceiro lugar, os tecidos de indivíduos afetados geralmente têm uma carência importante de fibrilina-1, muito menor que 50\% do normal, consequiência já prevista da perda da contribuição de um alelo. Em quarto lugar, alguns pacientes que possuem mutações 
Id on Line Revista Multidisciplinar e de Psicologia

Id on Line Multidisciplinary and Psycology Journal

associadas com baixa produção da proteína mutante apresentam uma variante leve da doença, muitas vezes subdiagnosticada ${ }^{(8,9)}$.

Algumas evidências sugerem que a haploinsuficiência da proteína normal pode ser mais crítica para manifestação clínica da doença que a produção da proteína mutante. Primeiro, porque a expressão transgênica exagerada da fibrilina-1 mutante, na presença de dois alelos normais do FBN1 em ratos, não foi suficiente para causar as alterações vasculares da SM, em comparação com ratos que possuíam uma mutação pontual. Segundo, porque ratos heterozigotos para um alelo nulo do FBN1 apresentaram alterações na estrutura da parede da aorta semelhantes aos ratos que possuíam a alteração pontual. E terceiro, porque a adição de um alelo transgênico "selvagem" aos ratos heterozigotos para a mutação pontual corrigiu as suas alterações aórticas ${ }^{(10)}$. Embora a redução da quantidade de microfibrilas imposta pela haploinsuficiência possa ou não, isoladamente, ser suficiente para produzir a SM clássica, ela já demonstra ser um ponto chave para que o efeito dominante negativo alcance um significado clinico importante. A partir desses dados, sugere-se que o aumento da expressão da fibrilina-1 pode ser uma boa estratégia terapêutica que implicaria na modulação da gravidade da doença através de manipulação genética.

Ao contrário do que se acreditava antes, os modelos murinos têm mostrado que não são necessárias as microfibrilas de fibrilina-1 para montar uma fibra elástica. A crença de que crianças afetadas nasciam sem fibras elásticas, gerando uma predisposição estrutural que cursaria inevitavelmente para a deficiência tecidual, prejudicou o desenvolvimento de estratégias eficientes de tratamento. Durante a vida pós-natal, entretanto, as microfibrilas são necessárias para manter as conexões das fibras elásticas. Quando da ausência das ligações entre as fibras elásticas e as células musculares lisas mediadas pela fibrilina-1, as células anormais assumem um padrão de síntese de enzimas que degradam a matriz, como as metaloproteinases 2 e 9. Essa anormalidade gera, subsequentemente, calcificação das fibras elásticas, inflamação da parede do vaso, hiperplasia da camada íntima (devido à proliferação de células musculares lisas) e colabamento da parede do vaso ${ }^{(11)}$.

Além do papel estrutural da fibrilina-1, tem ficado cada vez mais claro que as microfibrilas também desenvolvem um papel importante na regulação de citocinas $^{(12)}$. A fibrilina-1 possui um alto grau de semelhança com as proteínas que se ligam ao fator transformador de crescimento $\beta$ (TGF- $\beta$ ). O TGF- $\beta$ é produzido como grandes complexos que 
Id on Line Revista Multidisciplinar e de Psicologia

Id on Line Multidisciplinary and Psycology Journal

contém o peptídeo associado à latência (LAP), uma das três proteínas de ligação ao TGF- $\beta$, além do próprio TGF- $\beta$. Ao ser secretado, esse complexo é seqüestrado pela matriz extracelular e a semelhança da fibrilina- 1 com as proteínas de ligação ao TGF- $\beta$ fortalece a hipótese de que as microfibrilas podem participar da regulação de sua atividade ${ }^{(13)}$.

Algumas das alterações no sistema pulmonar podem ser justificadas por esta teoria. Concentrações elevadas de TGF- $\beta$ têm sido relacionadas com o aumento do espaço aéreo distal, sem inflamação ou destruição alveolar. E a administração de anticorpo neutralizante de TGF foi relatada com suficiente para corrigir a septação. Parece bem provável que esse mecanismo também seja responsável por outras manifestações da SM, como alterações da válvula mitral, alterações craniofaciais e crescimento exagerado dos ossos. Recentemente, o aumento da atividade local de TGF- $\beta$ tem sido responsabilizado pelo desenvolvimento de doença valvar $^{(14,15,16)}$. Quando da administração do anticorpo neutralizante de TGF- $\beta$ em modelos de SM em ratos, a disfunção da válvula atrioventricular é evitada. Em outros tecidos como o sistema vascular e a dura-máter também foram registrados aumento da atividade de TGF- $\beta^{(14,15)}$.

\section{Alterações Sistêmicas}

\section{Sistema esquelético:}

A mais evidente das alterações é o crescimento exagerado dos ossos longos. Isso produz uma deformidade torácica anterior, causada pelo crescimento excessivo das costelas, que empurram o esterno seja anteriormente (cariniforme) ou posteriormente (escavado). O crescimento excessivo de braços e pernas pode levar a um aumento da relação envergadura/altura maior que 1,05 ou a uma redução da relação segmento superior/segmento inferior do corpo (na ausência de escoliose grave). Aracnodactilia (crescimento exagerado dos dedos) geralmente é um achado subjetivo. A associação de dedos longos e hipermobilidade articular leva à pesquisa do sinal de Walker-Murdoch ou sinal de punho, que é a sobreposição total das falanges distais do dedo mínimo e do polegar quando enrolados no punho contralateral; e à pesquisa do sinal de Steinberg ou sinal do polegar, que ocorre quando a falange distal do polegar se estende totalmente para além da borda medial da palma da mão quando cruzado 
Id on Line Revista Multidisciplinar e de Psicologia

Id on Line Multidisciplinary and Psycology Journal

sobre ela. Apesar de comumente presente, a escoliose toracolombar deve ser suficientemente grave (maior que $20^{\circ}$ ) para se encaixar nos critérios do sistema esquelético. A protrusão acetabular, geralmente assintomática em jovens adultos, é mais identificada com radiografia $^{(3,16)}$.

O pé plano é frequente e varia de leve e assintomático a uma deformidade tão grave que chega a causar distúrbios de quadril e joelho, geralmente em decorrência do deslocamento medial do maléolo medial. Apesar de ser frequente a frouxidão ligamentar e hipermobilidade articular, podemos encontrar indivíduos com articulações normais e até contraturadas. Uma das contribuições para considerarmos maior comprometimento do sistema esquelético é a redução da extensão do cotovelo (menor que $\left.170^{\circ}\right)^{(3,16)}$.

Em crianças com SM grave e rapidamente progressiva, observamos comumente contratura dos dedos. As manifestações craniofaciais são freqüentes, mas não são suficientemente específicas para incluí-las nos critérios maiores. São elas: dolicocefalia (crânio longo e estreito), palato ogival com apinhamento dentário, retrognatismo ou micrognatia e achatamento malar ${ }^{(3,16)}$.

\section{Sistema Ocular:}

Um importante critério no diagnóstico da SM é a subluxação do cristalino, de qualquer grau. A ectopia do cristalino foi mostrada em cerca de $60 \%$ dos pacientes. Ainda encontram-se outras manifestações, como miopia precoce e grave, aplanamento de córnea, aumento do comprimento axial do globo, íris hipoplásica e hipoplasia do músculo ciliar, causando diminuição da miose. Os indivíduos afetados também podem ter descolamento de retina e uma predisposição para catarata precoce ou glaucoma ${ }^{(3,18,19)}$.

\section{Sistema Cardiovascular:}

As manifestações cardiovasculares da SM são convenientemente divididas entre aquelas que afetam o coração e as que afetam os vasos. Dentro do coração, as válvulas atrioventriculares (AV) são mais freqüentemente afetadas. O espessamento das AV é comum e está 
Id on Line Revista Multidisciplinar e de Psicologia

Id on Line Multidisciplinary and Psycology Journal

freqüientemente associado com prolapso de uma ou de ambas as válvulas, podendo ter regurgitação em graus variáveis ${ }^{(20)}$.

Em crianças o início precoce geralmente é sinal de gravidade, podendo evoluir para insuficiência valvar ou cardíaca congestiva, hipertensão pulmonar e morte súbita na infância. Esta insuficiência representa a principal causa de morbimortalidade em crianças afetadas. Estima-se que mais da metade dessas crianças possui evidência auscultatória ou ecocardiográfica de disfunção valvar mitral, mais comumente prolapso. Muitos destes indivíduos evoluem para prolapso mitral com regurgitação na idade adulta, chegando a prevalência a ser duas vezes maior entras as mulheres ${ }^{(21)}$. É importante frisar que achados de calcificação do anel mitral em indivíduos menores de 40 anos constitui um critério menor do sistema cardiovascular.

As disfunções da válvula aórtica é geralmente um achado tardio, atribuído ao estiramento do anel aórtico por um aneurisma de raiz em expansão. Tanto a válvula aórtica quanto a mitral parecem ser mais propensas à calcificação em indivíduos afetados ${ }^{(22)}$. Arritmias supraventriculares, como a fibrilação atrial, estão associadas com a disfunção mitral e vários estudos têm descrito aumento da prevalência de prolongamento do intervalo QT em pacientes $\operatorname{afetados}^{(23)}$

A cardiomiopatia dilatada também parece ocorrer com maior prevalência em pacientes afetados, muito provavelmente pela disfunção promovida pelo mau funcionamento da fibrilina1. Entretanto, a prevalência é baixa e a disfunção leve e moderada do ventrículo esquerdo parece ser atribuída à insuficiência mitral ou aórtica ou por uso de $\beta$-bloqueadores ${ }^{(24,25,26)}$.

Em termos de risco de vida, o aneurisma e a dissecção de aorta continuam a ser as mais graves manifestações da Síndrome de Marfan. Como são achados que dependem da idade, é necessário o monitoramento através de ecocardiograma ou outros exames de imagem. Em casos graves, a dilatação dos seios de Valsalva pode começar na vida intraútero. Embora alguns indivíduos afetados nunca precisem de intervenção cirúrgica, é preciso atentar para esta alteração. Em contraste com os aneurismas ateroscleróticos e outras formas de aneurismas da aorta ascendente, a dilatação é geralmente maior e muitas vezes restrita a raiz da aorta. As dimensões da raiz da aorta variam de acordo com a idade e com o tamanho do corpo ${ }^{(24)}$. Os dois importantes determinantes do risco de dissecção da aorta são a dimensão máxima da mesma e o histórico familiar de dissecção. Quando o diâmetro chega a $50 \mathrm{~mm}$ em adultos, é 
Id on Line Revista Multidisciplinar e de Psicologia

Id on Line Multidisciplinary and Psycology Journal

recomendado o reparo cirúrgico ${ }^{(24)}$. Só é recomendada uma intervenção na infância se houver histórico familiar de dissecção precoce. Infelizmente não há nenhum método definitivo para orientar o momento da cirurgia na infância, felizmente é raro observarmos dissecção nesta faixa etária. Ainda assim, muitos centros adotam o critério de adultos (diâmetro maior que $50 \mathrm{~mm}$ ) para indicar a cirurgia ${ }^{(23,24)}$.

O aparecimento de insuficiência cardíaca congestiva de início agudo geralmente está associado à insuficiência grave de válvula aórtica, evoluindo frequentemente para dissecção. Dependendo do grau de envolvimento das carótidas, alguns pacientes podem ter seqüelas neurológicas e o envolvimento das coronárias pode levar a infarto agudo do miocárdio e morte súbita. O mecanismo pelo qual o paciente evolui a óbito é pela ruptura do saco pericárdico e posterior tamponamento cardíaco $^{(26,27,28)}$.

A dilatação da artéria pulmonar, na ausência de estenose valvular pulmonar ou periférica, ou qualquer outra causa óbvia, em indivíduos menores de 40 anos, constitui um critério menor no sistema cardiovascular. A dilatação ou a dissecção da aorta descendente em indivíduos menores de 50 anos também são consideradas um critério menor no sistema cardiovascular, como já foi dito.

\section{Sistema Pulmonar:}

Em pacientes com Síndrome de Marfan, vários fatores podem resultar em doença pulmonar. Tórax escavado e escoliose progressiva podem contribuir para um padrão de doença pulmonar restritiva. O pneumotórax espontâneo é predisposto pela dilatação dos espaços aéreos distais, frequentemente no ápice, com ou sem bolhas, e é encontrado em 4 a 15\% dos pacientes afetados. Na avaliação da função pulmonar do paciente com SM é preciso atentar para o fato de que, em longo prazo, o crescimento excessivo dos ossos das extremidades inferiores pode levar à redução da capacidade vital forçada $(\mathrm{CVF})$ e da capacidade pulmonar total $(\mathrm{CPT})^{(29,30)}$.

\section{Sistema tegumentar:}

Contrastando com outras doenças do tecido conectivo, como a síndrome de EhlersDanlos, pacientes com Síndrome de Marfan geralmente têm textura e elasticidade da pele 
Id on Line Revista Multidisciplinar e de Psicologia

Id on Line Multidisciplinary and Psycology Journal

normal. A mais comum manifestação é atrofia estriada (estria), que ocorre em cerca de dois terços dos pacientes. Essas alterações costumam ocorrer na ausência de obesidade, gravidez e hipertrofia muscular. Outra manifestação comum é a hérnia inguinal, quer de origem neonatal ou adquirida na adolescência, sendo a recidiva frequente ${ }^{(31)}$.

\section{Diagnóstico}

Infelizmente, a testagem genética como método diagnóstico permanece limitada. Até hoje, mais de 500 mutações que dão origem à doença foram catalogadas ${ }^{(32)}$. E mesmo as famílias onde todos os indivíduos afetados compartilham a mesma mutação, a variação fenotípica é muito grande, dificultando o estabelecimento comparativo entre genótipo e fenótipo $^{(9,33)}$. O fato do gene FBN1 ser muito grande torna o custo do teste muito alto, impossibilitando ele de entrar na rotina padrão de análise. Entretanto, a análise de um haplótipo segregado é mais fácil de ser feita, e pode nos dá a informação que indique qual membro da família possui a cópia de gene mutante ${ }^{(1,21)}$.

A mutação da FBN1 pode causar muitas outras condições como a Síndrome de Shprintzen-Goldberg, prolapso da válvula mitral, fenótipo MASS, ectopia de cristalino familiar, entre outras (todas explicadas posteriormente). A severidade da apresentação da doença não é fator determinante para quantificar a natureza e a localização da mutação. Isso gera uma estimativa de que aproximadamente $10 \%$ das mutações que causam a Síndrome de Marfan clássica não são identificadas pelos métodos tradicionais de mapeamento ${ }^{(9)}$. Os testes genéticos apresentam baixa sensibilidade e especificidade, tornando a análise mutacional direta um parâmetro mais preciso de identificação da mutação e muito útil no diagnóstico pré-natal ${ }^{(34)}$. Contudo, o diagnóstico atualmente é basicamente clínico.

A SM tem uma apresentação multissistêmica com manifestações envolvendo principalmente os sistemas cardiovascular, esquelético e ocular. O diagnóstico é multidisciplinar, necessitando geralmente de um Geneticista, um Oftalmologista e um Cardiologista. O consenso sobre os critérios diagnósticos foi definido em Berlim, no Encontro Internacional de Doenças Hereditárias do Tecido Conectivo, em 1986. Entretanto, muitos indivíduos diagnosticados com a doença não carregavam a mutação do gene $F B N 1$, e os que 
apresentavam a mutação eram mais severamente afetados. Isso levou a uma revisão dos critérios, tornando-os mais rigorosos e específicos. Atualmente, os critérios dão maior ênfase nos achados esqueléticos e no pré-requisito de que a história familiar só pode ser considerada um critério maior para o diagnóstico do probando se, pelo menos, um membro da família satisfaça os critérios diagnósticos baseados apenas nas manifestações clínicas.

Para melhor entendimento dos critérios diagnósticos, é necessário que se saiba como utilizar os critérios maiores e menores, da seguinte maneira:

\section{Caso índice:}

- Se a história familiar não for positiva, é necessário um critério maior em dois sistemas com comprometimento de um terceiro sistema para fechar o diagnóstico.

- Se a mutação for identificada em um familiar, é necessário um critério maior em apenas um sistema com comprometimento de um segundo sistema para fechar o diagnóstico.

\section{Definição de critérios para cada sistema:}

\section{Sistema Esquelético:}

Critérios maiores (pelo menos quatro dos itens a seguir):

- Tórax cariniforme;

- Tórax escavado, necessitando correção cirúrgica;

- Redução da razão segmento superior/segmento inferior do corpo ou razão envergadura/altura maior que 1,05 ;

- Sinais de punho e polegar;

- Escoliose maior que $20^{\circ}$ ou espondilolistese;

- Extensão de cotovelo reduzida (menor que $170^{\circ}$ );

- Descolamento medial do maléolo medial, causando pés planos;

- Protrusão acetabular de qualquer grau (verificada na radiografia).

\section{Critérios menores:}

- Tórax escavado de severidade moderada;

- Hipermobilidade articular; 
- Palato altamente arqueado com apinhamento dos dentes;

- Aparência facial (dolicocefalia, enoftalmia, hipoplasia malar, retrognatia, fendas palpebrais inferiores inclinadas).

É considerado comprometimento do sistema esquelético quando encontramos, pelo menos, dois critérios maiores, ou um critério maior e dois critérios menores.

\section{Sistema ocular:}

\section{Critério maior:}

- Ectopia de cristalino.

\section{Critérios menores:}

- Córnea anormalmente plana;

- Comprimento axial do globo aumentado;

- Íris hipoplásica ou hipoplasia do músculo ciliar, causando diminuição da miose.

É considerado envolvimento do sistema ocular quando encontramos, pelo menos, dois critérios menores.

\section{Sistema cardiovascular:}

\section{Critérios maiores:}

- Dilatação da aorta ascendente, com ou sem regurgitação e envolvendo, pelo menos, o seio de Valsalva;

- Dissecção de aorta ascendente.

\section{Critérios menores:}

- Prolapso de válvula mitral com ou sem regurgitação;

- Dilatação da artéria pulmonar em menores de 40 anos, na ausência de estenose valvar ou periférica ou qualquer outra causa óbvia;

- Calcificação do anel mitral em menores de 40 anos;

- Dilatação ou dissecção da aorta descendente em menores de 50 anos.

É considerado comprometimento do sistema cardiovascular quando encontramos, pelo menos, um critério menor. 
Id on Line Revista Multidisciplinar e de Psicologia

Id on Line Multidisciplinary and Psycology Journal

\section{Sistema pulmonar:}

Critérios menores (não há critérios maiores):

- Pneumotórax espontâneo

- Bolhas apicais

É considerado comprometimento do sistema pulmonar quando encontramos, pelo menos, um critério menor.

\section{Sistema tegumentar:}

Critérios menores (não há critérios maiores):

- Estrias sem ganho de peso acentuado, gravidez ou esforço repetitivo;

- Hérnia incisional recorrente.

É considerado comprometimento do sistema tegumentar quando encontramos, pelo menos, um critério menor.

\section{Outros critérios maiores:}

- Pai, filho ou irmão que atendam de forma independente a esses critérios de diagnóstico;

- Presença da mutação do gene FBN1;

- Presença de haplótipo da mutação em descendentes.

\section{Diagnóstico Diferencial}

Com base nas manifestações sistêmicas já citadas, várias doenças podem ser incluídas no diagnóstico diferencial da Síndrome de Marfan. Muitos indivíduos, apesar de apresentarem quadros muito sugestivos, não satisfazem os critérios de diagnóstico, podendo confundir o profissional médico. Esses indivíduos são enquadrados como portadores de fenótipo MASS, uma sigla em inglês utilizada para determinar manifestações em conjunto de alterações da válvula Mitral, Aortic (aorta), Skin (pele) e Skeletal (esquelético) ${ }^{(35)}$. Esse fenótipo pode segregar em grandes populações e permanecer estável ao longo do tempo, tornando o seu diagnóstico ainda mais desafiador. É importantíssimo saber distinguir o fenótipo MASS da SM em seu início, especialmente em crianças. Manifestações subclínicas de outras fibrilinopatias, 
Id on Line Revista Multidisciplinar e de Psicologia

Id on Line Multidisciplinary and Psycology Journal

como Ectopia de Cristalino Familiar e a Síndrome do Prolapso da Válvula Mitral Familiar também podem ser devido a mutações no gene que codifica a fibrilina- $1^{(36)}$.

Homocistinúria, que é causada por uma deficiência da enzima cistationina sintase ou da metionina sintase, também entra no diagnóstico diferencial. Esses pacientes cursam com alta estatura, crescimento excessivo de ossos longos e subluxação de cristalino, entretanto não costumam cursar com alargamento da aorta nem dissecção da mesma. É uma herança autossômica recessiva e os indivíduos afetados frequentemente têm aterosclerose coronariana, predisposição para tromboembolismo e apresentam retardo mental. Altas concentrações plasmáticas de homocistina geralmente diferenciam muito bem uma da outra ${ }^{(37)}$.

A Síndrome do Aneurisma de Aorta Torácica Familiar é segregada como um traço dominante e pode se manifestar de forma idêntica aos sintomas cardiovasculares da SM. Esses indivíduos, entretanto, não apresentam outras manifestações sistêmicas ${ }^{(38)}$. Alguns trabalhos mostram uma associação entre válvula aórtica bicomissural e aneurisma de aorta ascendente, que também pode segregar como traço dominante. Há uma evidência emergente de que ambos representem manifestações primárias de uma única alteração genética ${ }^{(39)}$. Mais uma vez, esses indivíduos não apresentam outras manifestações sistêmicas características de uma doença do tecido conjuntivo, além de mostrarem penetrância variável, ao contrário da SM. Porém, apesar de ter sido descrito um loci gênico para essa associação, não existe ainda um gene específico ou um teste molecular que confirme, sendo obrigado o acompanhamento permanente desses pacientes e de seus familiares ${ }^{(37)}$.

A Síndrome de Loeys-Dietz (SLD) se apresenta também com aneurisma de aorta, hipoplasia malar, retrognatismo, palato arqueado, escoliose, frouxidão articular e deformidade de tórax. Embora tenham dedos longos, o crescimento dos ossos longos pode ser sutil e muitas vezes ausente. Nesses pacientes não encontramos ectopia de cristalino, e tem sido demonstrada uma alta freqüência de hipertelorismo, tortuosidade arterial, úvula bífida e aneurisma com dissecção ao longo de toda árvore arterial. Outras características menos consistentes são pele translúcida, esclera azul, fenda palatina, craniosinostose, Malformação de Chiari tipo I, pé torto, déficit de aprendizagem e algumas cardiopatias congênitas (persistência do canal arterial, comunicação interatrial e válvula aórtica bicomissural $)^{(40)}$.

Algumas características da SLD se sobrepõem com a Síndrome de Shprintzen-Goldberg (SSG), como craniosinostose, palato arqueado, hipertelorismo, déficit de aprendizagem, 
Id on Line Revista Multidisciplinar e de Psicologia

Id on Line Multidisciplinary and Psycology Journal

crescimento excessivo dos ossos longos e escoliose. Entretanto, manifestações vasculares são raras na SSG. Devido ao comportamento agressivo das alterações vasculares, distinguir a SLD é essencial para a individualização do manejo ${ }^{(41)}$.

\section{Manejo e Aconselhamento Genético}

Após o estabelecimento do diagnóstico, é de rotina a monitoração do crescimento aórtico através de exame de ecocardiografia com intuito de diminuir o risco de aneurisma e dissecção da mesma e indicar o tempo apropriado da intervenção cirúrgica. Entretanto, em pacientes com deformidades severas de tronco é indicado o acompanhamento com angiotomografia ou RNM, devido à limitação do eco em visualizar a aorta descendente nesses casos. Sempre que o tamanho da aorta estiver próximo do indicado para cirurgia, é prudente também que se façam exames com intervalos mais curtos a fim de evitar quadros $\operatorname{agudos}^{(3,9,22,42)}$.

Deve-se lembrar também que, devido ao risco de dissecção aguda da aorta, os pacientes devem ser aconselhados a não praticar esportes de contato ou competitivos. Morte súbita em atletas de ponta que possuem formas discretas de SM tem nos mostrado a importância do diagnóstico precoce. Porém, a maioria dos pacientes deve ser estimulada a praticar atividades aeróbicas moderadas, pois promoverá uma melhor qualidade da função cardiovascular e esquelética $^{(42)}$

Além da ectopia de cristalino ser um critério maior para o diagnóstico, os pacientes têm um risco aumentado de descolamento de retina, catarata e glaucoma. A miopia também é relatada na maioria dos pacientes e pode estar associada a uma maior predisposição de amaurose na infância ${ }^{(18,19)}$. O descolamento de retina pode ser prevenido com uso de óculos ou lentes de contato, entretanto pode ser necessária cirurgia corretiva para uma melhor acuidade visual, utilizando próteses ${ }^{(18,19)}$.

Os defeitos ortopédicos mais severos devem ser acompanhados por um Ortopedista especializado. A escoliose progressiva frequentemente requer correção cirúrgica ${ }^{(43)}$. Alguns estudos mostram que as correções cirúrgicas para as deformidades torácicas não têm mostrado efeito significativo sobre a doença pulmonar restritiva instalada, entretanto melhoram a capacidade funcional do coração ${ }^{(29,30)}$. 
$\mathrm{O}$ fato de a doença ser de origem genética, alerta para o risco de recorrência e transmissão do gene defeituoso. O aconselhamento genético é parte fundamentação da orientação ao paciente e a gravidez requer uma atenção redobrada. Há um risco de transmissão de $50 \%$ nos casos em que apenas um dos pais é afetado. Antes das cirurgias de correção de aorta, acreditava-se que havia um risco maior de dissecção durante a gravidez ${ }^{(21,44)}$. Hoje, sabese que esse risco está mais relacionado com o tamanho da raiz da aorta antes da gravidez, reduzido em pacientes com aorta menor que $40 \mathrm{~mm}$.Por fim, o problema da anticoagulação em pacientes grávidas com prótese valvar. A warfarina é conhecidamente teratológica e tem mostrado seus efeitos ao longo dos anos. A heparina de baixo peso molecular, administrada por via subcutânea, apesar de não atravessar a barreira placentária, pode resultar em trombocitopenia e pode não prevenir a trombose valvar. Um acompanhamento criterioso de um Obstetra e de um Cardiologista é essencial ${ }^{(44)}$.

\section{Considerações Finais}

Até então, a visão de que pessoas com Síndrome de Marfan nascem com um defeito estrutural que obrigatoriamente aumentaria o risco de falência tecidual dificulta a elaboração de soluções e piora o prognóstico dessas pessoas. As novas descobertas que identificam manifestações pós-natais semelhantemente a uma patologia adquirida, são um forte indicativo de que há uma falha na regulação (e não estrutural) da matriz extracelular, promovendo prognósticos muito mais otimistas. Com exceção da ectopia de cristalino, a maioria das manifestações da SM parece ser justificada pela desregulação da atividade do TGF- $\beta$ e, em modelos animais, as alterações foram modificadas no período pós-natal através da manipulação da sua atividade. Alguns tratamentos com drogas ainda em desenvolvimento podem não só reduzir a progressão dos aneurismas de aorta, bem como a patogênese da SM.

A evolução técnico-científica dos últimos anos nos garantiu um melhor entendimento das causas, da fisiopatologia e do tratamento da SM. À medida que aumenta o esclarecimento acerca das conseqüências da deficiência de fibrilina-1, há uma melhora na expectativa e na qualidade de vida dos afetados. A decodificação do genoma humano ainda trará novas possibilidades para a elucidação da base genética desta doença. Os profissionais precisam estar 
Id on Line Revista Multidisciplinar e de Psicologia

Id on Line Multidisciplinary and Psycology Journal

atentos à modificação da história natural da Síndrome de Marfan, para que respondam com eficiência às novas situações, que provavelmente envolverão a predisposição a doenças articulares precoces e as doenças da aorta torácica em idosos.

\section{Referências}

1. Aalberts JJ, Schuurman AG, Pals G, Hamel BJ, Bosman G, Hilhorst-Hofstee Y, et al. Recurrent and founder mutations in the Netherlands: Extensive clinical variability in Marfan syndrome patients with a single novel recurrent fibrillin-1 missense mutation. Neth Heart J. $2010 \mathrm{Feb} ; 18(2): 85-9$.

2. Giese EA, O'Connor FG, Brennan FH, Depenbrock PJ, Oriscello RG. The athletic preparticipation evaluation: cardiovascular assessment. Am Fam Physician. 2007 Apr 1;75(7):1008-14.

3. Ha HI, Seo JB, Lee SH, Kang JW, Goo HW, Lim TH, Shin MJ. Imaging of Marfan syndrome: multisystemic manifestations. Radiographics. 2007 Jul-Aug;27(4):989-1004.

4. Fazio MJ, Mattei MG, Passage E, Chu ML, Black D, Solomon E, et al. Human Elastin Gene: New Evidence for Localization to the Long Arm of Chromosome 7. Am. J. Hum. Genet. 48:696-703, 1991.

5. Vanita V, Singh JR, Singh D, Varon R, Robinson PN, Sperling K. A recurrent FBN1 mutation in an autosomal dominant ectopia lentis family of Indian origin. Mol Vis. 2007 Oct 25;13:2035-40.

6. Challa P, Hauser MA, Luna CC, Freedman SF, Pericak-Vance M, Yang J, et al. Juvenile bilateral lens dislocation and glaucoma associated with a novel mutation in the fibrillin 1 gene. Mol Vis. 2006 Aug 28;12:1009-15.

7. Whiteman P, Handford PA. Defective secretion of recombinant fragments of fibrillin-1: implications of protein misfolding for the pathogenesis of Marfan syndrome and related disorders. Hum Mol Genet. 2003 Apr 1;12(7):727-37.

8. Nijbroek G, Sood S, McIntosh I, Francomano CA, Bull E, Pereira L, et al. Fifteen novel FBN1 mutations causing Marfan syndrome detected by heteroduplex analysis of genomic amplicons. Am J Hum Genet. 1995 Jul;57(1):8-21.

9. Faivre L, Collod-Beroud G, Loeys BL, Child A, Binquet C, Gautier E, et al. Effect of mutation type and location on clinical outcome in 1,013 probands with Marfan syndrome or related phenotypes and FBN1 mutations: an international study. Am J Hum Genet. 2007 Sep;81(3):454-66. Epub 2007 Jul 25. 
Id on Line Revista Multidisciplinar e de Psicologia

Id on Line Multidisciplinary and Psycology Journal

10. Judge DP, Biery NJ, Keene DR, Geubtner J, Myers L, Huso DL, et al. Evidence for a critical contribution of haploinsufficiency in the complex pathogenesis of Marfan syndrome. $\mathrm{J}$ Clin Invest. 2004 Jul;114(2):172-81.

11. Bunton TE, Biery NJ, Myers L, Gayraud B, Ramirez F, Dietz HC. Phenotypic alteration of vascular smooth muscle cells precedes elastolysis in a mouse model of Marfan syndrome. Circ Res. 2001 Jan 19;88(1):37-43.

12. Jordan CD, Charbonneau NL, Sakai LY. Fibrillin microfibrils: connective tissue pathways that regulate shape and signaling. J Musculoskelet Neuronal Interact. 2006 Oct-Dec;6(4):3667.

13. Ramirez F, Sakai LY. Biogenesis and function of fibrillin assemblies. Cell Tissue Res. 2010 Jan;339(1):71-82. Epub 2009 Jun 10.

14. Wang Y, Ait-Oufella H, Herbin O, Bonnin P, Ramkhelawon B, Taleb S, et al. TGF-beta activity protects against inflammatory aortic aneurysm progression and complications in angiotensin II-infused mice. J Clin Invest. 2010 Feb;120(2):422-32. doi: 10.1172/JCI38136. Epub 2010 Jan 25.

15. Chaudhry SS, Cain SA, Morgan A, Dallas SL, Shuttleworth CA, Kielty CM. Fibrillin-1 regulates the bioavailability of TGFbeta1. J Cell Biol. 2007 Jan 29;176(3):355-67. Epub 2007 Jan 22.

16. Habashi JP, Judge DP, Holm TM, Cohn RD, Loeys BL, Cooper TK, Myers L, Klein EC, Liu G, Calvi C, Podowski M, Neptune ER,Halushka MK, Bedja D, Gabrielson K, Rifkin DB, Carta L, Ramirez F, Huso DL, Dietz HC. Losartan, an AT1 antagonist, prevents aortic aneurysm in a mouse model of Marfan syndrome. Science. 2006 Apr 7;312(5770):117-21.

17. Adib N, Davies K, Grahame R, Woo P, Murray KJ Joint hypermobility syndrome in childhood. A not so benign multisystem disorder? Rheumatology (Oxford). 2005 Jun;44(6):744-50. Epub 2005 Feb 22.

18. Sultan G, Baudouin C, Auzerie O, De Saint Jean M, Goldschild M, Pisella PJ; Marfan Study Group. Cornea in Marfan disease: Orbscan and in vivo confocal microscopy analysis. Invest Ophthalmol Vis Sci. 2002 Jun;43(6):1757-64.

19. Challa P, Hauser MA, Luna CC, Freedman SF, Pericak-Vance M, Yang J, et al. Juvenile bilateral lens dislocation and glaucoma associated with a novel mutation in the fibrillin 1 gene. Mol Vis. 2006 Aug 28;12:1009-15.

20. De Backer J. The expanding cardiovascular phenotype of Marfan syndrome. Eur J Echocardiogr. 2009 Mar;10(2):213-5. Epub 2008 Dec 23.

21. Faivre L, Masurel-Paulet A, Collod-Béroud G, Callewaert BL, Child AH, Stheneur C, et al. Clinical and molecular study of 320 children with Marfan syndrome and related type I 
Id on Line Revista Multidisciplinar e de Psicologia

Id on Line Multidisciplinary and Psycology Journal

fibrillinopathies in a series of 1009 probands with pathogenic FBN1 mutations. Pediatrics. 2009 Jan;123(1):391-8.

22. Keane MG, Pyeritz RE. Medical management of Marfan syndrome. Circulation. 2008 May 27;117(21):2802-13.

23. Wren C. Screening children with a family history of sudden cardiac death. Heart. 2006 Jul;92(7):1001-6.

24. Milewicz DM, Dietz HC, Miller DC. Treatment of aortic disease in patients with Marfan syndrome. Circulation. 2005 Mar 22;111(11):e150-7.

25. Zehr KJ, Orszulak TA, Mullany CJ, Matloobi A, Daly RC, Dearani JA, et al. Surgery for aneurysms of the aortic root: a 30-year experience. Circulation. 2004 Sep 14;110(11):1364-71. Epub 2004 Aug 16.

26. Kiotsekoglou A, Sutherland GR, Moggridge JC, Kapetanakis V, Bajpai A, Bunce N, et al. Impaired right ventricular systolic function demonstrated by reduced atrioventricular plane displacement in adults with Marfan syndrome. Eur J Echocardiogr. 2009 Mar;10(2):295-302. Epub 2008 Sep 18.

27. Tsai SH, Lin YY, Hsu CW, Chen YL, Liao MT, Chu SJ. The characteristics of acute aortic dissection among young Chinese patients: a comparison between Marfan syndrome and nonMarfan syndrome patients. Yonsei Med J. 2009 Apr 30;50(2):239-44.

28. Mulder BJ. The distal aorta in the Marfan syndrome. Neth Heart J. 2008 Nov;16(11):3826.

29. Pearson GD, Devereux R, Loeys B, Maslen C, Milewicz D, Pyeritz R, et al. National Heart, Lung, and Blood Institute and National Marfan Foundation Working Group. Report of the National Heart, Lung, and Blood Institute and National Marfan Foundation Working Group on research in Marfan syndrome and related disorders. Circulation. 2008 Aug 12;118(7):785-91.

30. Baran S, Ignyś A, Ignyś I. Respiratory dysfunction in patients with Marfan syndrome. J Physiol Pharmacol. 2007 Nov;58 Suppl 5(Pt 1):37-41.

31. Yao Z, Jaeger JC, Ruzzo WL, Morale CZ, Emond M, Francke U, et al. A Marfan syndrome gene expression phenotype in cultured skin fibroblasts. BMC Genomics. 2007 Sep 12;8:319.

32. Collod-Béroud G, Béroud C, Ades L, Black C, Boxer M, Brock DJ, et al. Marfan Database (third edition): new mutations and new routines for the software. Nucleic Acids Res. 1998 Jan $1 ; 26(1): 229-3$.

33. Disabella E, Grasso M, Marziliano N, Ansaldi S, Lucchelli C, Porcu E, et al. Two novel and one known mutation of the TGFBR2 gene in Marfan syndrome not associated with FBN1 gene defects. Eur J Hum Genet. 2006 Jan;14(1):34-8. 
Id on Line Revista Multidisciplinar e de Psicologia

Id on Line Multidisciplinary and Psycology Journal

34. Akutsu K, Morisaki H, Takeshita S, Sakamoto S, Tamori Y, Yoshimuta T, et al. Phenotypic heterogeneity of Marfan-like connective tissue disorders associated with mutations in the transforming growth factor-beta receptor genes. Circ J. 2007 Aug;71(8):1305-9.

35. Arslan-Kirchner M, von Kodolitsch Y, Schmidtke J. The importance of genetic testing in the clinical management of patients with marfan syndrome and related disorders. Dtsch Arztebl Int. 2008 Jul;105(27):483-91. Epub 2008 Jul 4.

36. Wren C. Screening for potentially fatal heart disease in children and teenagers. Heart. 2009 Dec;95(24):2040-6.

37. Summers KM, West JA, Peterson MM, Stark D, McGill JJ, West MJ. Challenges in the diagnosis of Marfan syndrome. Med J Aust. 2006 Jun 19;184(12):627-31.

38. [No authors listed] Acute aortic dissection in a young patient without Marfan fibrillinopathy: a case report. Cases J. 2009 Apr 28;2:7076.

39. De Sá MP, Bastos ES, Murad H. Bicuspid aortic valve: theoretical and clinical aspects of concomitant ascending aorta replacement. Rev Bras Cir Cardiovasc. 2009 Jun;24(2):218-24.

40. Choo JT, Tan TH, Lai AH, Wong KY. Loeys-Dietz syndrome: a Marfan-like syndrome associated with aggressive vasculopathy. Singapore Med J. 2009 Oct;50(10):e353-7.

41. Onrat ST, Emmiler M, Sivaci Y, Söylemez Z, Ozgöz A, Imirzalioğlu N. A patient with ascending aortic dilatation, similar to phenotypes of connective tissue disorders. Genet Mol Res. 2009 Apr 14;8(2):426-34.

42. Dean JC. Marfan syndrome: clinical diagnosis and management. Eur J Hum Genet. 2007 Jul;15(7):724-33. Epub 2007 May 9.

43. Glard Y, Launay F, Edgard-Rosa G, Collignon P, Jouve JL, Bollini G. Scoliotic curve patterns in patients with Marfan syndrome. J Child Orthop. 2008 Jun;2(3):211-6. Epub 2008 Mar 15.

44. Goland S, Elkayam U. Cardiovascular problems in pregnant women with marfan syndrome. Circulation. 2009 Feb 3;119(4):619-23

\section{Como citar este artigo (Formato ABNT):}

MARX, M.; SIMÕES NETO, E.A.; ALVES, M.N.T.; LANDIM, J.M.M.; BEZERRA, M.M.M. Síndrome de Marfan. Id on Line Revista Multidisciplinar e de Psicologia, Janeiro de 2017, vol.10, n.33, Supl 2. p. 01-19. ISSN: 1981-1179.

Recebido: 17/12/2016

Aceito: 04/01/2017 